\title{
Effect of High Pressure Homogenization on the Physicochemical Properties of Natural Plant-based Model Emulsion Applicable for Dairy Products
}

\author{
Sung Hee Park ${ }^{1}$, Sang-Gi Min ${ }^{2}$, Yeon-Ji Jo ${ }^{2 *}$, and Ji-Yeon Chun ${ }^{3 *}$ \\ ${ }^{I}$ Department of Marine Food Science and Technology, Gangneung-Wonju National University, \\ Gangneung 25457, Korea \\ ${ }^{2}$ Department of Bioindustrial Technologies, Konkuk University, Seoul 05029, Korea \\ ${ }^{3}$ Department of Food Bioengineering, Jeju National University, Jeju 63243, Korea
}

\begin{abstract}
In the dairy industry, natural plant-based powders are widely used to develop flavor and functionality. However, most of these ingredients are water-insoluble; therefore, emulsification is essential. In this study, the efficacy of high pressure homogenization (HPH) on natural plant (chocolate or vanilla)-based model emulsions was investigated. The particle size, electrical conductivity, Brix, $\mathrm{pH}$, and color were analyzed after HPH. HPH significantly decreased the particle size of chocolate-based emulsions as a function of elevated pressures (20-100 MPa). HPH decreased the mean particle size of chocolate-based emulsions from $29.01 \mu \mathrm{m}$ to $5.12 \mu \mathrm{m}$, and that of vanilla-based emulsions from $4.18 \mu \mathrm{m}$ to $2.44 \mu \mathrm{m}$. Electrical conductivity increased as a function of the elevated pressures after HPH, for both chocolate- and vanilla-based model emulsions. HPH at $100 \mathrm{MPa}$ increased the electrical conductivity of chocolate-based model emulsions from $0.570 \mathrm{~S} / \mathrm{m}$ to $0.680 \mathrm{~S} / \mathrm{m}$, and that of vanilla-based model emulsions from $0.573 \mathrm{~S} / \mathrm{m}$ to $0.601 \mathrm{~S} / \mathrm{m}$. Increased electrical conductivity would be attributed to colloidal phase modification and dispersion of oil globules. Brix of both chocolate- and vanilla-based model emulsions gradually increased as a function of the HPH pressure. Thus, HPH increased the solubility of plant-based powders by decreasing the particle size. This study demonstrated the potential use of HPH for enhancing the emulsification process and stability of the natural plant powders for applications with dairy products.
\end{abstract}

Keywords: high pressure homogenization, dairy products, natural plant powder, emulsion, particle size

Received March 24, 2015; Revised August 11, 2015; Accepted August 16, 2015

\section{Introduction}

The natural plant-based dairy products market has steadily increased over the past decade because of the health effects and functionality of products such as chocolate- and vanilla-milk. Cocoa and its chocolate extract have recently been recognized as rich sources of flavonoids, mainly flavanols, which are potent antioxidant and anti-inflammatory agents with established benefits for cardiovascular health but with largely unproven effects on neurocognition and behavior (Sokolov et al., 2013). Vanilla extracts have also been reported to possess

\footnotetext{
*Corresponding authors: Ji-Yeon Chun, Department of Food Bioengineering, Jeju National University, Jeju 63243, Korea. Tel: +82-10-8707-4494, Fax: +82-64-754-2465, E-mail: cjswldus00 @naver.com

Yeon-Ji Jo, Department of Bioindustrial Technologies, Konkuk University, Seoul 05029, Korea. Tel: +82-2-450-3672, 3680, Fax: +82-2-455-1044, E-mail: whduswl86@naver.com
}

various health benefits, such as antioxidant, antimutagenic, and hypolipidemic activity, and have considerable potential as food preservatives and anticarcinogens (AlNaqeb et al., 2010; Andrade et al., 1992; Dong et al., 2014; Jadhav et al., 2009; Sharma et al., 2006). However, most ingredients in these plant-based powders are unsuitable for use in dairy product applications due to lack of solubility. The conventional method for production of chocolate- or vanilla-milk involves addition of chocolate or vanilla powder to raw milk with stabilizers (sodium alginate, carrageenans, or amylum) and synthetic emulsifiers (monoglyceride, diglyceride, synthetic phospholipids-YN). Nowadays, the food industry has a growing interest in the replacement of synthetic emulsifiers because consumers prefer naturally processed products (Garti, 1999; Perrechil and Cunha, 2010). High pressure homogenization $(\mathrm{HPH})$ is one of the more prominent technologies used to increase the aqueous solubility of functional ingredients and emulsion stability without the

(9)This is an open access article distributed under the terms of the Creative Commons Attribution Non-Commercial License (http://creativecommons.org/licences/ by-nc/3.0) which permits unrestricted non-commercial use, distribution, and reproduction in any medium, provided the original wokr is properly cited. 
requirement for synthetic emulsifiers (Bader et al., 2011; Bouaouina et al., 2006; Grácia-Juliá, 2008; Paquin, 1999). Drop size and its distribution in an emulsion must be reduced to enhance solubility, stability, mouth feel, and reaction intensity. $\mathrm{HPH}$ has been found to be the most efficient means to create emulsions with submicron-sized particles and to increase protein solubility in dairy products (Bader et al., 2011).

A high pressure homogenizer consists of a high pressure piston pump, which creates a pressure of 10-500 $\mathrm{MPa}$, and a narrow gap through which the emulsion is accelerated to high velocities $\left(>10^{2} \mathrm{~m} / \mathrm{s}\right)$. HPH has demonstrated improved quality aspects, such as enhanced colloidal stability and microbial and enzymatic inactivation, compared with conventional homogenization at 20-50 MPa (Cruz et al., 2007; Poliseli-Scopel et al., 2013). HPH consists of pressurizing a fluid to flow quickly through a narrow-gap valve, which greatly increases its velocity and results in depressurization with consequent cavitation and high shear stress. Thus, particles, cells, and macromolecules suspended in the fluid are subjected to high mechanical stress and become twisted and deformed (Augusto et al., 2012; Floury et al., 2004; Pinho et al., 2011). This study was carried out to investigate the efficacy of HPH (20-100 MPa) on the emulsifying characteristics of chocolate- and vanillabased model emulsions without synthetic emulsifiers for application in dairy products.

\section{Materials and Methods}

\section{Sample preparation}

Chocolate- and vanilla-powder-based model emulsions were prepared on the day of use prior to HPH. The formulations of the chocolate and vanilla products are summarized in Table 1. Chocolate- or vanilla-powder was gradually added into distilled water at $74^{\circ} \mathrm{C}$ within $8 \mathrm{~min}$ by using immersion blender (6FVD0, Waring Pro, USA). After mixing the power, fat crystals melted into canola oil $\left(88^{\circ} \mathrm{C}\right)$ and flavor were added and mixed for $4 \mathrm{~min}$. The temperature of sample was carefully maintained at $74^{\circ} \mathrm{C}$ before HPH. A mixing temperature of $74^{\circ} \mathrm{C}$ was selected to prevent coagulation of the model emulsions. The total mixing time did not exceed $15 \mathrm{~min}$.

\section{High pressure homogenization (HPH)}

Homogenization treatments were carried out on a laboratory-scale high pressure homogenizer (M-110Y, Microfluidics, USA). In this system, the processing pressure
Table 1. Formulation of chocolate and vanilla beverage products

\begin{tabular}{ccc}
\hline \hline Ingredients & $\%(\mathrm{w} / \mathrm{w})$ & $\%(\mathrm{v} / \mathrm{w})$ \\
\hline Chocolate or Vanilla powder & 13.33 & \\
Canola oil & 1.04 & \\
Fat crystal & 0.19 & \\
Flavor & & 0.21 \\
Water & & 85.23 \\
\hline
\end{tabular}

ranged from 20 to $150 \mathrm{MPa}$ with a flow rate of $100-500$ $\mathrm{mL} / \mathrm{min}$. The sample-feed temperature ranged from 25 to $75^{\circ} \mathrm{C}$. The homogenizer was equipped with an air regulator, intensifier pump, interaction chamber (F20Y), and an auxiliary processing module (H30Z). The product stream enters the interaction chamber and passes through geometrically fixed microchannels for shear and impact. The auxiliary processing module provided additional processing support for the homogenization. A cooling coil cooled the sample immediately after HPH.

Chocolate- or vanilla-emulsions at $74^{\circ} \mathrm{C}$ were loaded into sample reservoir, and then homogenized at 20, 40, 60,80 , and $100 \mathrm{MPa}$. The homogenized samples passed through a cooling coil surrounded by an ice/water mixture and were cooled to $16-25^{\circ} \mathrm{C}$. After homogenization, the samples were further cooled to $4^{\circ} \mathrm{C}$ in an ice/water mixture.

\section{Characterization of the model emulsions}

\section{Particle size}

Particle size in the model emulsions was measured by laser light-scattering experiments with a Mastersizer instrument (MICRO-P, United Kingdom). The sample was added dropwise into distilled water until $25 \%$ obscuration (HPH-cv-2). Emulsion particle sizes were expressed as the volume-weighted diameter $\left(D_{4,3}=n_{\mathrm{i}} d_{\mathrm{i}}^{4} / n_{\mathrm{i}} d_{\mathrm{i}}{ }^{3}\right)$ and as a particle-size distribution, in which $n_{\mathrm{i}}$ is the number of particles of diameter $d_{\mathrm{i}}$.

\section{Electrical conductivity}

Electrical conductivities of the model emulsions were determined by using an LCZ meter (4277 A, Agilent Technologies, USA). The sample ( $5 \mathrm{~mL}$ ) was loaded into a cylindrical polycarbonate sample holder (diameter: 12.7 $\mathrm{mm}$, length: $67 \mathrm{~mm}$ ), and platinum-plated titanium electrodes were installed at both ends. The distance between the electrodes was $39.5 \mathrm{~mm}$ (this length was used for calculation of the cell constant). The LCZ meter provided the electrical resistance of the sample at $1-\mathrm{kHz}$ frequency, selected to prevent double-layer capacitance and any 
polarizing effect on the electrodes and inside the samples (Braunstein and Robbins, 1967; Min et al., 2007; Park et al., 2013). Electrical conductivity was calculated by using Equation (1) (Rieger, 1994).

$$
\sigma=k \times \frac{1}{R}=\frac{L}{A} \times \frac{1}{R}
$$

in which $A$ is the area of sample holder, $L$ is the distance between the electrodes, $k$ is the cell constant (estimated as $312 \mathrm{~m}^{1}$ ), and $R$ is the electrical resistance.

\section{Sugar content $\left({ }^{\circ} \mathrm{Bx}\right), \mathrm{pH}$, and color}

Changes in color, sugar content, and $\mathrm{pH}$ were conducted by using a colorimeter (ColorQuest XE, HunterLab, USA), refractometer (Brix/RI-Check, USA), and $\mathrm{pH}$ meter (FG-2, Mettler Toledo, USA), respectively.

\section{Statistical analysis}

The data was analyzed by using SAS 9.1.3 software (SAS Inst. Inc., USA). Fisher's least-significant difference (LSD) procedure was used for multiple comparisons among treatments at the $95 \%$ confidence interval $(p<0.05)$. To evaluate the relationship between particle size $(P S)$ and electrical conductivity $(E)$, the experimental results were empirically fitted to first- and second-order polynomial regressions by using SAS, as described in Equations (2) and (3).

$$
\begin{aligned}
& P S=\beta_{0}+\beta_{1} \cdot E \pm \varepsilon \\
& P S=\beta_{0}+\beta_{1} \cdot E+\beta_{2} \cdot E^{2} \pm \varepsilon
\end{aligned}
$$

\section{Results and Discussion}

\section{Particle size and distribution}

Fig. 1 shows the changes in particle size of chocolateand vanilla-milk after HPH. HPH significantly decreased the particle size of chocolate milk as a function of elevated pressure. The mean particle size of the chocolatebased control was $29.01 \pm 2.96 \mu \mathrm{m}$, which decreased to $5.12 \pm 0.09 \mu \mathrm{m}$ at $100 \mathrm{MPa}$. $\mathrm{HPH}$ at $20,40,60,80$, and $100 \mathrm{MPa}$ reduced the particle size of the chocolate milk by $79,80,81,81$, and $83 \%$, respectively. HPH induces deformation and disruption of the emulsion droplets; thus, particle size decreases as the sample passes through the homogenizing valve. The fluid passes through a minute gap in the homogenizing valve during HPH. This creates conditions of high turbulence and shear, which, united with compression, acceleration, pressure drop, and

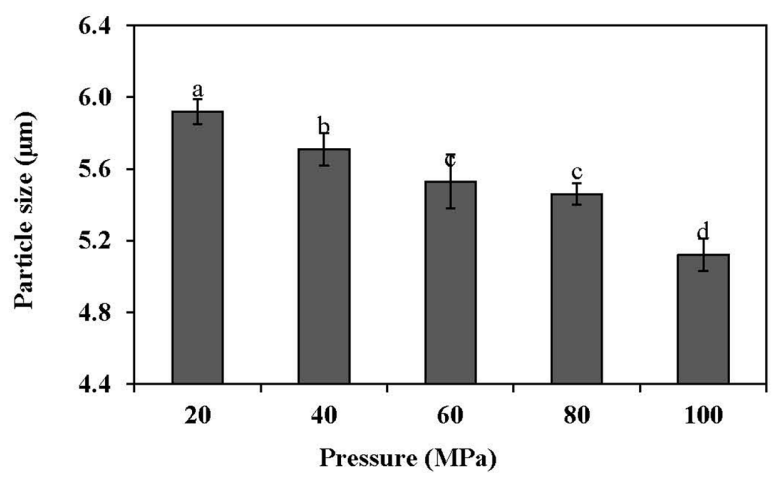

(a)

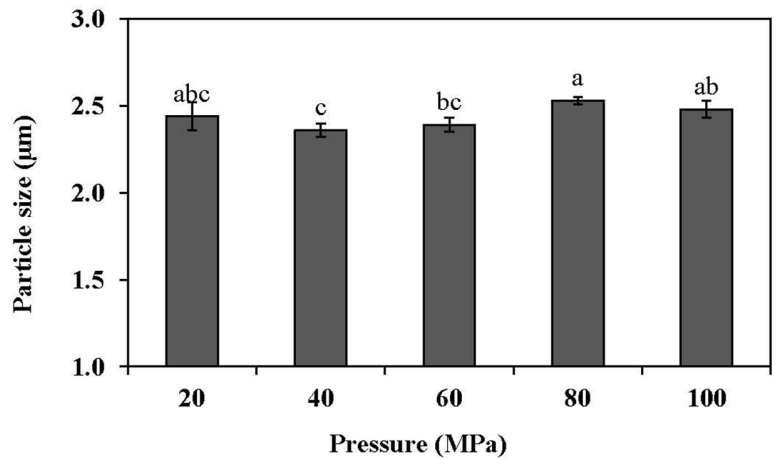

(b)

Fig. 1. Mean particle size of (a) chocolate and (b) vanilla based products subjected to high-pressure homogenization (20-100 MPa).

impact, break down the particles and disperse them all over the product (Majzoobi et al., 2013). In general, elevated pressures in HPH are more effective to decrease the size of emulsion droplets (Qian and McClements, 2011; Tan and Nakajima, 2005; Tcholakova et al., 2003). HPH decreased the particle size of the vanilla-based emulsion from $4.18 \pm 0.06 \mu \mathrm{m}$ (control) to $2.44 \pm 0.08 \mu \mathrm{m}(20-\mathrm{MPa}$ treatment). Increasing the HPH treatment pressure further did not reduce the particle size in vanilla milk. Base ingredients and initial particle size could influence the efficacy of HPH. The particle size of the vanilla milk control sample was $4.18 \mu \mathrm{m}$, which is significantly smaller than that of chocolate milk $(29.01 \mu \mathrm{m})$. The tiny initial particle size of the vanilla milk would prevent further size reduction with increasing HPH pressure.

\section{Changes in electrical conductivity after HPH}

Fig. 2 showed the changes in electrical conductivities of chocolate- and vanilla-milk after HPH. HPH increased the electrical conductivities of both chocolate- and vanillabased emulsions as a function of elevated pressure. HPH at $100 \mathrm{MPa}$ increased the electrical conductivity of the 


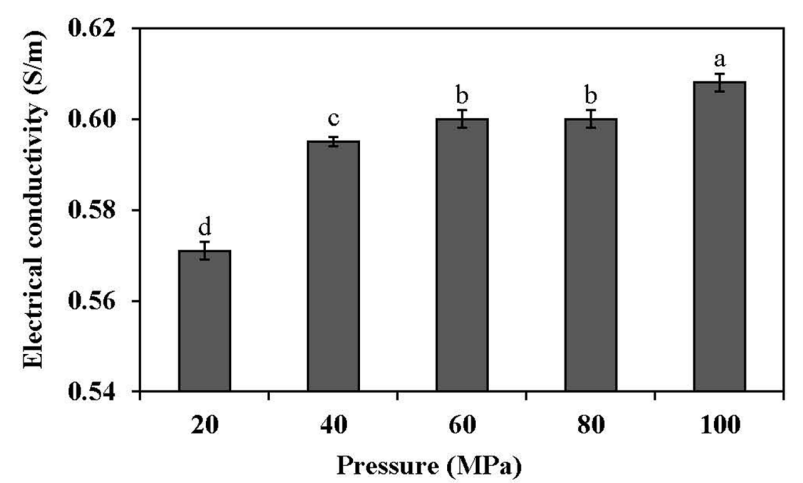

(a)

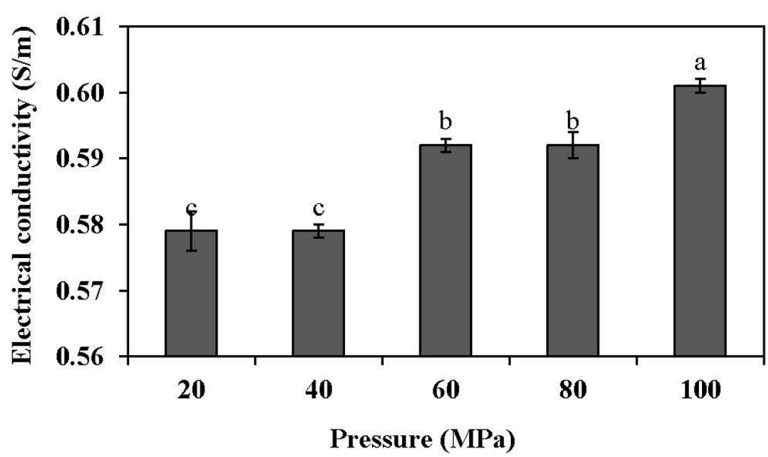

(b)

Fig. 2. Changes in electrical conductivity of (a) chocolate and (b) vanilla based products subjected to high-pressure homogenization (20-100 MPa).

chocolate-based model emulsion control sample from $0.570 \mathrm{~S} / \mathrm{m}$ to $0.680 \mathrm{~S} / \mathrm{m}$, and that of the vanilla-based model emulsion from $0.573 \mathrm{~S} / \mathrm{m}$ (control sample) to $0.601 \mathrm{~S} / \mathrm{m}$. Increased electrical conductivity would allow colloidal-phase modification and dispersion of oil globules in water. Electric current is due to the flow of charge carried by ions (Shirsat et al., 2004). Thus, the electrical conductivity of a liquid depends on the amount of ions that can move freely in the liquid. Homogenization leads to lower particle size and higher negative charge of the dispersed particles, which indicates that compounds are arranged in the dispersed phase (Bernat et al., 2011). In our study, an inverse relationship between particle size and electrical conductivity was found. Electrical conductivity could explain the emulsion characteristics in relation to the particle size in liquid foodstuffs. The relationship between particle size and electrical conductivity was fitted to a first- and second-order polynomial (Equations (2) and (3)); the results are given in Table 2. The chocolatebased model emulsion showed negative linear coefficients, $\beta_{1}$ and $\beta_{2}$, which indicated an inverse relationship between particle size and electrical conductivity in the firstand second-order polynomial, respectively. However, the inverse relationship between particle size and electrical conductivity in the vanilla-based model emulsion showed no statistically significant relationship $(p>0.05)$. This might be attributed to the fixed particle size in the vanillabased model emulsion at HPH pressures above $20 \mathrm{MPa}$. Although pressures above $20 \mathrm{MPa}$ did not influence the particle size, the electrical conductivity significantly increased at elevated pressures $(p<0.05)$. Therefore, electrical conductivity measurements could be a more-sensitive approach than measurement of the particle size to detect the emulsion status.

\section{Particle size and distribution}

Fig. 3 shows the influence of HPH on the particle-size distribution of the chocolate- and vanilla-based model emulsions. The distribution for the chocolate-based model emulsion control sample peaked at the larger particle sizes $(10-12 \mu \mathrm{m})$. In comparison, after HPH peaks were observed at smaller particle size with a bimodal distribution. This implies that HPH results in a smaller particle-

Table 2. Estimated coefficients and probability test of the fitted first and second order polynomial parameters between particle size $(P S)$ and electrical conductivity $(E)\left(P S=\beta_{0}+\beta_{1}, P S=\beta_{0}+\beta_{1} \cdot E+\beta_{2} \cdot \mathbf{E}^{2} \pm \varepsilon\right)$

\begin{tabular}{cccccc}
\hline \hline & & \multicolumn{2}{c}{ Chocolate powder } & \multicolumn{2}{c}{ Vanilla powder } \\
\cline { 2 - 5 } & & Coefficients & $\operatorname{Pr}>|t|$ & Coefficients & Pr $>|t|$ \\
\hline \multirow{3}{*}{$1^{\text {st }}$ order model } & $\beta_{0}$ & $16.85^{*}$ & 0.0001 & 0.029 & 0.98 \\
& $\beta_{1}$ & $-18.99^{*}$ & 0.0001 & 4.090 & 0.04 \\
& $R^{2}$ values & 0.74 & 0.28 & \\
& SSEY () & 0.15 & 0.07 & -54.42 & 0.50 \\
$2^{\text {nd }}$ order model & $\beta_{0}$ & $-273.65^{*}$ & 0.0021 & 0.49 \\
& $\beta_{1}$ & $969.57^{*}$ & 0.0016 & -157.74 & 0.50 \\
& $\beta_{2}$ & $-840.54^{*}$ & 0.0014 & & \\
& $R^{2}$ values & 0.89 & 0.31 & & \\
& SSEY () & 0.10 & & &
\end{tabular}

* Significant at $95 \%$ confidence interval 


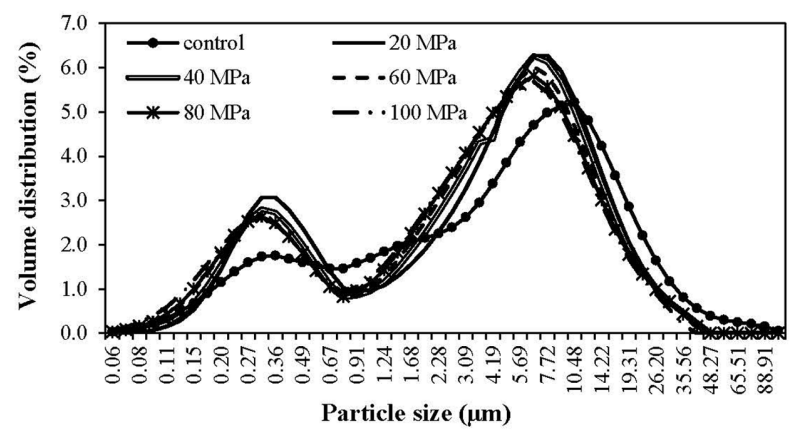

(a)

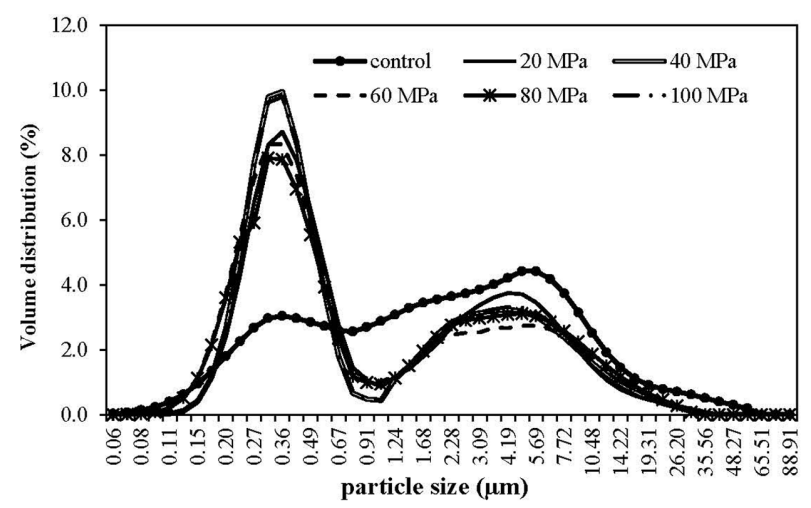

(b)

Fig. 3. Particle size distribution of (a) chocolate and (b) vanilla based products subjected to high-pressure homogenization (20-100 MPa).

size distribution. However, the particle size distributions obtained at the various homogenization pressures were not significantly different. There could be a threshold homogenization pressure, above which there is no further decrease in particle size. For the chocolate-based model, $20 \mathrm{MPa}$ is the threshold point within the scope of our experiment.

In the vanilla-based model emulsion, the particle size of the control sample had an overall distribution from small to large particles. HPH induced a bimodal distribution with a higher peak at smaller particle size. The distribution of the emulsion particles in whey protein emulsion became more bimodal after HPH, which indicated droplet-droplet aggregation (Kuhn and Cunha, 2012). The higher peak at smaller particle size proved the efficacy of HPH for emulsion stability.

Figs. 4 and 5 show the changes in color of chocolateand vanilla-based products influenced by the HPH pressure. HPH at $20 \mathrm{MPa}$ increased the $L^{*}$ value of the chocolate-based model emulsion, which subsequently decreased with further increases in pressure (Fig. 4). The $L^{*}$ value of milk generally increases as a function of elevated

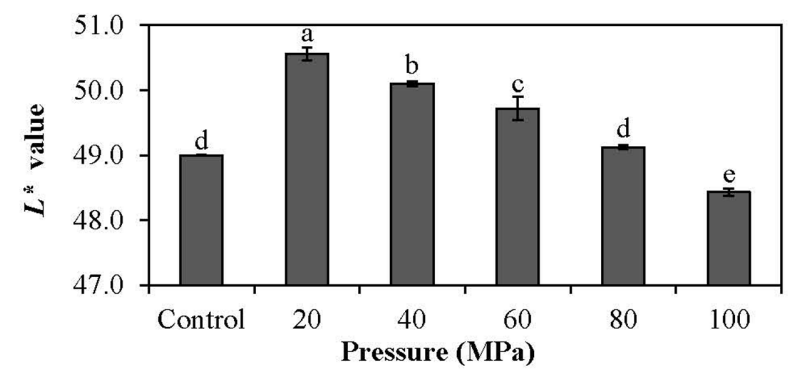

(a)

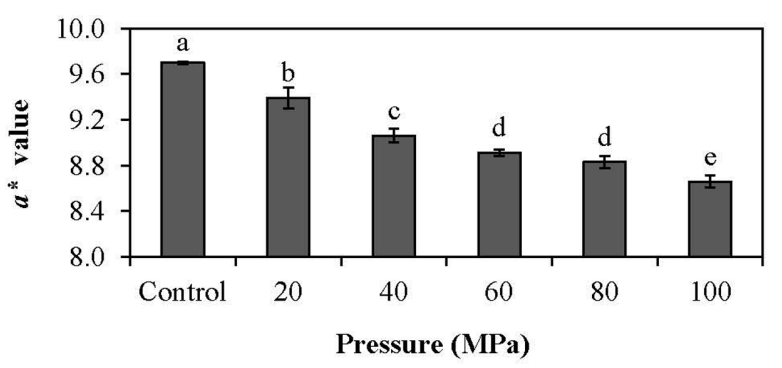

(b)

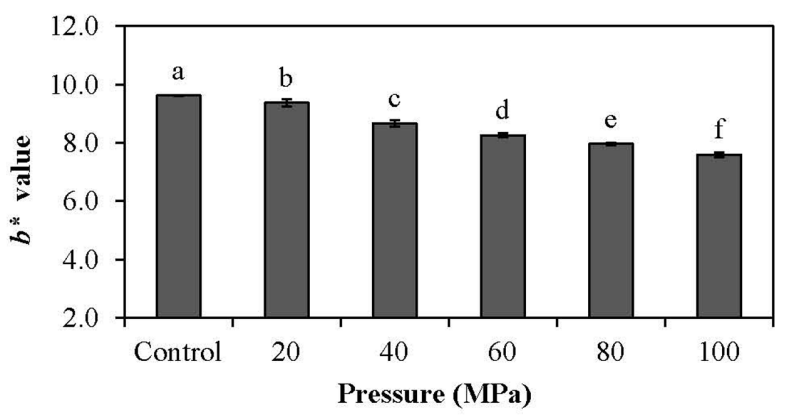

(c)

Fig. 4. Changes in color of chocolate based products subjected to high-pressure homogenization (20-100 MPa).

pressure during HPH (Amador-Espejo et al., 2014; Hayes et al., 2005; Pereda et al., 2007). The increased $L^{*}$ value is due to an increased number of fat globules, which can diffract light more effectively (Walstra et al., 2006). HPH decreased both the $a^{*}$ and $b^{*}$ values of the chocolatebased model emulsion as a function of HPH pressure (Fig. 4). The decreased $a^{*}$ and $b^{*}$ values might be directly related to the decreased $L^{*}$ values. The color changes of the vanilla-based model emulsion are shown in Fig. 5. The $L^{*}$ value significantly decreased with increased HPH pressures $(p<0.05)$. The result is contradictory to that for the chocolate-based model. The different ingredients in the model emulsion would influence the color values differently. HPH decreased both the $a^{*}$ and $b^{*}$ values of the vanilla-based model emulsion as a function of pressure. 


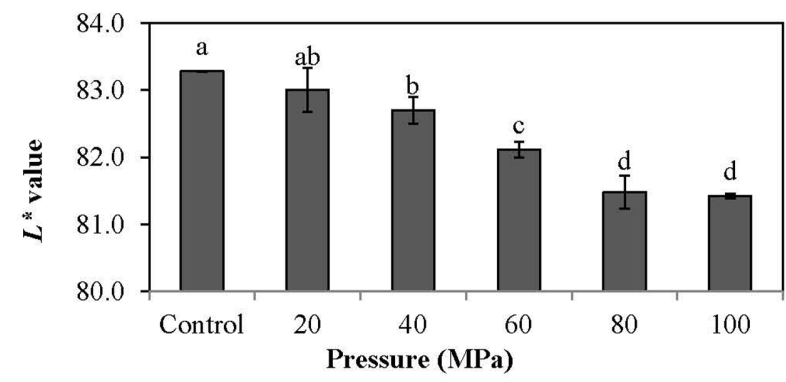

(a)

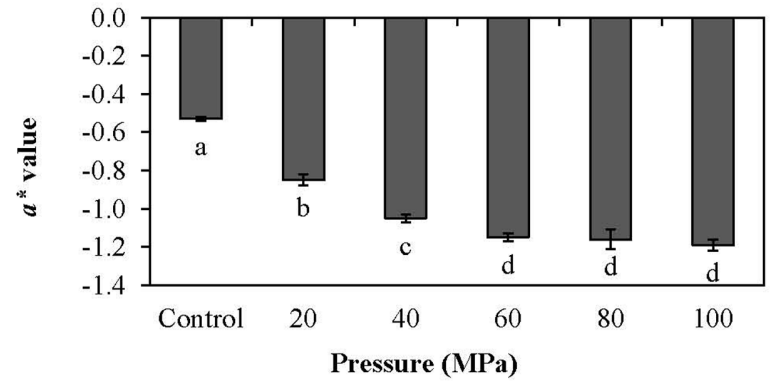

(b)

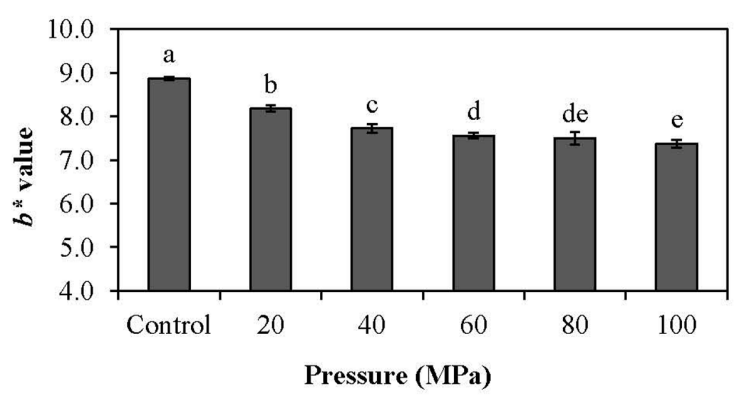

(c)

Fig. 5. Changes in color of vanilla based products subjected to high-pressure homogenization (20-100 MPa).

Table 3 summarizes the changes in sugar content and $\mathrm{pH}$ during HPH. HPH significantly increased the Brix values of both the chocolate- and vanilla-based model emulsions as a function of elevated pressure $(p<0.05)$. In the chocolate-based model emulsion, the Brix value of the control sample was $12.9^{\circ} \mathrm{Bx}$, which increased up to $15.2^{\circ} \mathrm{Bx}$ at $100 \mathrm{MPa}$. The vanilla-based model emulsion control sample had $11.5^{\circ} \mathrm{Bx}$, which eventually increased to $14.6^{\circ} \mathrm{Bx}$ after $\mathrm{HPH}$ at $100 \mathrm{MPa}$. HPH increases the solubility of calcium- and phosphorus salts and their levels decrease in the colloidal form due to micelle disintegration to subunits and adsorption on the surface of milk-fat globules (Kielczewska et al., 2006). It was suggested that large protein aggregates dissociate at dynamic high pressures, which leads to unmasking of the buried hydrophobic groups without affecting the protein solu-
Table 3. Influence of HPH on dry basis moisture (\%), fat contents $(\%)$ and brix $\left({ }^{\circ} \mathrm{Bx}\right)$ of chocolate and vanilla based model emulsions

\begin{tabular}{cccc}
\hline \hline & & Chocolate based & Vanilla based \\
\hline & Control & $12.9 \pm 0.0^{\mathrm{f}}$ & $11.5 \pm 0.3^{\mathrm{d}}$ \\
& $20 \mathrm{MPa}$ & $13.5 \pm 0.1^{\mathrm{e}}$ & $13.4 \pm 0.2^{\mathrm{c}}$ \\
$\mathrm{Brix}$ & $40 \mathrm{MPa}$ & $14.1 \pm 0.1^{\mathrm{d}}$ & $14.1 \pm 0.1^{\mathrm{b}}$ \\
$\left({ }^{\circ} \mathrm{Bx}\right)$ & $60 \mathrm{MPa}$ & $14.3 \pm 0.2^{\mathrm{c}}$ & $13.9 \pm 0.2^{\mathrm{b}}$ \\
& $80 \mathrm{MPa}$ & $14.9 \pm 0.1^{\mathrm{b}}$ & $14.4 \pm 0.2^{\mathrm{a}}$ \\
& $100 \mathrm{MPa}$ & $15.2 \pm 0.1^{\mathrm{a}}$ & $14.6 \pm 0.1^{\mathrm{a}}$ \\
\hline \multirow{4}{*}{$\mathrm{Control}$} & $6.91 \pm 0.03^{\mathrm{b}}$ & $7.03 \pm 0.02^{\mathrm{a}}$ \\
& $20 \mathrm{MPa}$ & $6.94 \pm 0.02^{\mathrm{a}}$ & $6.97 \pm 0.03^{\mathrm{b}}$ \\
$\mathrm{pH}$ & $40 \mathrm{MPa}$ & $6.93 \pm 0.01^{\mathrm{ab}}$ & $6.99 \pm 0.02^{\mathrm{b}}$ \\
& $60 \mathrm{MPa}$ & $6.93 \pm 0.02^{\mathrm{ab}}$ & $6.97 \pm 0.01^{\mathrm{b}}$ \\
& $80 \mathrm{MPa}$ & $6.92 \pm 0.01^{\mathrm{ab}}$ & $6.98 \pm 0.01^{\mathrm{b}}$ \\
& $100 \mathrm{MPa}$ & $6.95 \pm 0.01^{\mathrm{a}}$ & $6.98 \pm 0.01^{\mathrm{b}}$ \\
\hline
\end{tabular}

bility (Grácia-Juliá et al., 2008). Increased macromolecule solubility would increase the Brix values of the chocolate- and vanilla model emulsions. HPH increased Brix values of chocolate and vanilla based model emulsions. This is a meaningful data since HPH increased the solubility of natural plant based powder for dairy product application. In our study, there were no clear HPHinfluenced changes in the $\mathrm{pH}$ of either the chocolate- or vanilla-based model emulsions.

\section{Conclusions}

HPH significantly decreased the particle size of the chocolate-based model emulsion from $29.01 \mu \mathrm{m}$ (control) to $5.12 \mu \mathrm{m}(100 \mathrm{MPa})$ as a function of elevated pressure (20-100 MPa). The particle size in the vanilla-based emulsion decreased from $4.18 \mu \mathrm{m}$ (control) to $2.44 \mu \mathrm{m}$ (20 MPa); however, no further reduction in particle size was observed at pressures above $20 \mathrm{MPa}$, which suggests that there is a pressure threshold for reduction of particle size by HPH. HPH apparently increased the electrical conductivity of both the chocolate- and vanilla-based model emulsions. The results suggest colloidal-phase modification and dispersion of the oil globules into water. In our study, electrical conductivity showed an inverse relationship to particle size. HPH induces deformation and disruption of the emulsion droplets, thus, particle size decreases during passage through the homogenizing valve. HPH induced increased Brix values of the model emulsions, which possibly enhances the solubility of macromolecules in the emulsion. This study demonstrates the potential use of HPH for enhancing the emulsion stability of natural plant-based beverages and their solubility, without requiring synthetic emulsifiers, for dairy- 
product applications.

\section{Acknowledgments}

The authors wish to thank Dr. VM Balasubramaniam at the Department of Food Science and Technology, The Ohio State University for proving the high pressure homogenizer. This research was partially supported by Unilever, New Jersey, USA. The authors are grateful for Dr. Khalid Farooq at Unilever for providing all the tested samples and technical communication.

\section{References}

1. Al-Naqeb, G., Ismail, M., Bagalkotkar, G., and Adamu, H. A. (2010) Vanillin rich fraction regulates LDLR and HMGCR gene expression in HepG2 cells. Food Res. Int. 43, 2437-2443.

2. Amador-Espejo, G. G., Suàrez-Berencia, A., Juan, B., Bárcenas, M. E., and Trujillo, A. J. (2014) Effect of moderate inlet temperatures in ultra-high-pressure homogenization treatments on physicochemical and sensory characteristics of milk. J. Dairy Sci. 97, 659-671.

3. Andrade, H. H. R., Santos, J. H., Gimmler-Luz, M. C., Correa, M. J. F., Lehmann, M., and Reguly, M. L. (1992) Suppressing effect of vanillin on chromosome aberrations that occur spontaneously or are induced by mitomycin $\mathrm{C}$ in the germ cell line of Drosophila melanogaster. Mutat. Res. 279, 281-287.

4. Augusto, P. E. D., Ibarz, A., and Cristianini, M. (2012) Effect of high pressure homogenization (HPH) on the rheological properties of tomato juice: Time-dependent and steady-state shear. J. Food Eng. 111, 570-579.

5. Bader, S., Bez, J., and Eisner, P. (2011) Can protein functionalities be enhanced by high-pressure homogenization? - A study on functional properties of lupin proteins. Procedia Food Sci. 1, 1359-1366.

6. Bernat, N., Chafer, M., Chiralt, A., and Gonzalez-Martínez, C. (2011) Effect of ultra-high pressure homogenization and heat treatment on physicochemical properties of almond beverage. International Conference on Food and Environment., Athens, Greece, pp. 152-156.

7. Bouaouina, H., Desrumaux, A., Loisel, C., and Legrand, J. (2006). Functional properties of whey proteins as affected by dynamic high pressure treatment. Int. Dairy J. 16, 275-284.

8. Cruz, N., Capellas, M., Hernández, M., Trujillo A. J., Guamis, B., and Ferragut, V. (2007). Ultra high pressure homogenization of soymilk: Microbiological, physicochemical and microstructural characteristics. Food Res. Int. 40, 725-732.

9. Dong, Z., Gu, F., Xu, F., and Wang, F. (2014) Comparison of four kinds of extraction techniques and kinetics of microwave-assisted extraction of vanillin from Vanilla planifolia Andrews. Food Chem. 149, 54-61.

10. Floury, J., Bellettre, J., Legrand, J., and Desrumaux, A. (2004) Analysis of a new type of high pressure homogeniser. A study of the flow pattern. Chem. Eng. Sci. 59, 843-853.
11. Garti, N. (1999) What can nature offer from an emulsifier point of view: Trends and progress? Colloids Surf. A. 152, 125-146.

12. Grácia-Juliá, A., René, M., Cortés-Muñoz, M., Picart, M., López-Pedemonte, T., Chevalier, D., and Dumay, E. (2008) Effect of dynamic high pressure on whey protein aggregation: A comparison with the effect of continuous short-time thermal treatments. Food Hydrocolloids. 22, 1014-1032.

13. Hayes, M. G., Fox, P. F., and Kelly, A. L. (2005) Potential applications of high pressure homogenisation in processing of liquid milk. J. Dairy Res. 72, 25-33.

14. Jadhav, D., Rekha, B. N., Gogate, P. R., and Rathod, V. K. (2009) Extraction of vanillin from vanilla pods: A comparison study of conventional soxhlet and ultrasound assisted extraction. J. Food Eng. 93, 421-426.

15. Kielczewska, K., Kruk, A., Czerniewicz, M., and Haponiuk, E. (2006) Effects of high-pressure homogenization on the physicochemical properties of milk with various fat concentrations. Pol. J. Food Nutr. Sci. 15, 91-94.

16. Kuhn, K. R. and Cunha, R. L. (2012) Flaxseed oil - Whey protein isolate emulsions: Effect of high pressure homogenization. J. Food Eng. 111, 449-457.

17. Majzoobi, M., Shahbazi, M., Farahnaky, A., Rezvani, E., and Schleining, G. (2013) Effects of high pressure homogenization on the physicochemical properties of corn starch. Inside Food Symposium, Leuven, Belgium, pp. 33-35.

18. Paquin, P. (1999) Technological properties of high pressure homogenizers: The effect of fat globules, milk proteins and polysaccharides. Int. Dairy J. 9, 329-335.

19. Perrechil, F. A. and Cunha, R. L. (2010) Oil-in-water emulsions stabilized by sodium caseinate: Influence of $\mathrm{pH}$, highpressure homogenization and locust bean gum addition. $J$. Food Eng. 97, 441-448.

20. Pinho, C. R. G., Franchi, M. A., Augusto, P. E. D., and Cristianini, M. (2011) Milk flow evaluation during high pressure homogenization (HPH) using computational fluid dynamics (CFD). Brazilian J. Food Technol. 14, 232-240.

21. Poliseli-Scopel, F. H., Hernández-Herrero, M., Guamis, B., and Ferragut, V. (2013) Characteristics of soymilk pasteurized by ultra high pressure homogenization (UHPH). Innov. Food Sci. Emerg. Technol. 20, 73-80.

22. Qian, C. and Julian McClements, D. (2011). Formation of nanoemulsions stabilized by model food-grade emulsifiers using high-pressure homogenization: Factors affecting particle size. Food Hydrocolloids. 25, 1000-1008.

23. Sharma, A., Verma, S. C., Saxena, N., Chadda, N., Singh, N. P., and Sinha, A. K. (2006) Microwave- and ultrasoundassisted extraction of vanillin and its quantification by highperformance liquid chromatography in Vanilla planifolia. $J$. Sep. Sci. 29, 613-619.

24. Shirsat, N., Lyng, J. G., Brunton, N. P., and McKenna, B. (2004) Ohmic processing: Electrical conductivities of pork cuts. Meat Sci. 67, 507-514.

25. Sokolov, A. N., Pavlova, M. A., Klosterhalfen, S., and Enck, P. (2013) Chocolate and the brain: Neurobiological impact of cocoa flavanols on cognition and behavior. Neurosci. Biobe- 
hav. Rev. 37, 2445-2453.

26. Tan, C. P. and Nakajima, M. (2005) beta-Carotene nanodispersions: preparation, characterization and stability evaluation. Food Chem. 92, 661-671.

27. Tcholakova, S., Denkov, N. D., Sidzhakova, D., Ivanov, I. B., and Campbell, B. (2003) Interrelation between drop size and protein adsorption at various emulsification conditions. Langmuir. 19, 5640-5649.

28. Walstra, P., Geurts, T. J., and Wouters, J. T. M. (2006) Dairy Science and Technology. CRC Press. FL, pp. 325-328. 